
\title{
25 Research Square \\ The prediction model of fatty liver was established by blood biochemical indexes
}

yan xu

Chinese PLA General Hospital https://orcid.org/0000-0003-0242-9751

Rong LIU ( $D$ L301liurong@126.com )

, Chinese People's Liberation Army (PLA) General Hospital, Beijing https://orcid.org/0000-0002-53210111

Research

Keywords: fatty liver, NHANES, Prediction model, Platelet count. glucose, ALT

Posted Date: November 23rd, 2021

DOI: https://doi.org/10.21203/rs.3.rs-1094067/v1

License: (1) This work is licensed under a Creative Commons Attribution 4.0 International License.

Read Full License 


\section{Abstract \\ Background}

The main cause of chronic liver disease is fatty liver, which includes alcoholic fatty liver and nonalcoholic fatty liver disease. This study is aimed to establish the prediction model of fatty liver, and provide help for the prevention and treatment of fatty liver, especially NAFLD in the future.

\section{Methods}

Datasets from 2017 to March 2020 NHANES required for the analysis were downloaded from the NHANES web site and R 4.1.1. Software was used for data analysis. A total of 3762 subjects were enrolled in this study, which were divided into model construction group and model validation group in a 2:1 ratio.

\section{Results}

The study selected 6 indicators to build the prediction model, which are as follows: ALT, Platelet count, Creatinine, LDH, HS C-Reactive Protein, Glucose. Then the prediction model was constructed. The area under ROC curve of the model was 0.7471 . In the validation population, the area under the ROC curve of the model was 0.7816 .

\section{Conclusions}

F score has a good predictive effect on fatty liver, which can be used as an important means for the prevention and treatment of fatty liver, especially NAFLD in the future.

\section{Introduction}

The main cause of chronic liver disease is fatty liver, which includes alcoholic fatty liver and nonalcoholic fatty liver disease (NAFLD). It includes complex pathological manifestations, from simple fat accumulation to non-alcoholic steatohepatitis (NASH), which is an important factor in other metabolic disorders, and also an important cause of type 2 diabetes and cardiovascular disease(1). In the United States, NAFLD has affected the lives of a quarter of people and has become the second leading cause of liver transplantation(2). Alcoholic liver disease is a related disease state characterized by early fatty liver (alcoholic steatosis). NAFLD and alcoholic steatohepatitis are both important causes of serious complications such as HCC and liver cirrhosis(3-6).

The pathophysiological feature of fatty liver is the accumulation of large amounts of fat in liver parenchymal cells (liver cells). Under normal circumstances, these cells are particularly adept at storage 
and excretion of fat to promote the body's metabolic needs. However, in disease states, they are prone to accumulate fat at a super-pathological level(1). NAFLD is characterized by excessive accumulation of triglycerides in the liver, which is a common complication of obesity and is related to insulin resistance and metabolic syndrome(7). According to MRI evaluation, more than $5 \%$ of the fat in the liver is considered to be early liver steatosis(8). It is characterized by lipid apoptosis, inflammation and fibrosis of liver cells(9).

The diagnosis of fatty liver requires imaging and histological examination, while the diagnosis of NAFLD is more complicated $(10,11)$. The initial challenge was when to suspect fatty liver, because most patients are asymptomatic. Due to the lack of cost-effective, non-invasive tests with high predictive value, and the lack of effective treatments, comprehensive NAFLD screening is not currently recommended(12).

Therefore, it is necessary to explore a new effective clinical prediction model for fatty liver, so that the high-risk population can change their lifestyle earlier, better prevent the occurrence of fatty liver and reduce the incidence of various complications. In this study, the clinical prediction model of fatty liver was established by using the database of National Health and Nutrition Examination Surveys (NHANES), and its good predictive effect was verified, which could become an important means for the prevention and treatment of fatty liver in the future.

\section{Methods}

\subsection{Study Sample}

Datasets from 2017 to March 2020 NHANES required for the analysis were downloaded from the NHANES web site. After excluding the information deficit group, a total of 3762 subjects were enrolled in this study, which were divided into model construction group and model validation group in a 2:1 ratio. The characteristics of the study population are shown in Table 1. 
Table 1

Characterization of the study population

Model building population Model validation population

Gender

male

female

Age

Race/Hispanic origin

Mexican American

Other Hispanic

Non-Hispanic White

Non-Hispanic Black

Other Race - Including Multi-Racial

ALT (IU/L)

Creatinine (umol/L)

Glucose (mmol/L)

Platelet count (1000 cells/uL)

fatty liver

have

none

$\mathrm{N}$
$1216(48.48 \%)$

1292(51.52\%)

$50.886 \pm 17.466$

$313(12.48 \%)$

258(10.29\%)

855(34.09\%)

$626(24.96 \%)$

$456(18.18 \%)$

$21.858 \pm 16.028$

$79.781 \pm 50.448$

$5.855 \pm 1.983$

$242.271 \pm 64.939$

65(2.59\%)

2443(97.41\%)

2508
$583(46.49 \%)$

671(53.51\%)

$50.426 \pm 17.455$

173(13.8\%)

119(9.48\%)

420(33.49\%)

$324(25.84 \%)$

218(17.38\%)

$21.494 \pm 16.31$

$78.064 \pm 39.511$

$5.924 \pm 2.042$

$243.785 \pm 64.918$

24(1.91\%)

1230(98.09\%)

1254

\subsection{Statistical analysis}

Analyses were conducted using R 4.1.1. A total of 59 laboratory tests and physical examination indicators such as body weight were included. After screening risk factors, the prediction model was incorporated to reflect the prediction accuracy by the area under the ROC curve, and the prediction accuracy of the model was verified in the validation population. Boostrap test was used for the prediction model, and repeated sampling was conducted for 500 times.

\section{Results}

\subsection{Screening of impact factors}


The 59 indexes were used for machine learning and predictive analysis. The influence of indexes on fatty liver was shown in Figure 1a. The Alignment Diagram of the influence of various factors on fatty liver can be seen in Figure 1b. We select the first 6 indicators to build the prediction model, which are as follows: Alanine Aminotransferase (ALT, IU/L) (VIF= 1.1), Platelet count (1000 cells/uL) (VIF=1.1), Creatinine, refrigerated serum (umol/L) (VIF= 1), Lactate Dehydrogenase (LDH) (IU/L) (VIF=1.1), HS C-Reactive Protein $(\mathrm{mg} / \mathrm{L})(\mathrm{VIF}=1.1)$, Glucose, refrigerated serum $(\mathrm{mmol} / \mathrm{L})(\mathrm{VIF}=1)$.

\subsection{Prediction model Construction}

The model was constructed with the included indicators in 2508 subjects.

F score $=-3.54200+0.27464 \times\left((\mathrm{ALT} / 10)^{\wedge} 1\right)-2.36968 \times\left((\text { Creatinine } / 100)^{\wedge} 1\right)+0.92544 \times\left((\text { Glucose } / 10)^{\wedge} 1\right)$ $+1.39671 \times\left((\text { Platelet count } / 100)^{\wedge}-2\right)$

ALT: IU/L, Creatinine: umol/L, Glucose: mmol/L, Platelet count: 1000 cells/uL.

The area under ROC curve of the model was 0.7471 , as shown in Figure $2.95 \% \mathrm{Cl}$ was $[0.6789,0.81]$, the optimal threshold was 0.0198 , the specificity was 0.5686 , the sensitivity was 0.8125 , the accuracy was 0.5749 , the positive likelihood ratio was 1.8834 , the negative likelihood ratio was 0.3298 . The diagnostic odds ratio was 5.7114 , positive predictive value was 0.0474 , and negative predictive value was 0.9914 . (Bootstrap resampling times $=500$ )

\subsection{Validation of prediction effect of prediction model}

ROC curves were also used to assess the predictive effect of $F$ score on fatty liver disease in 1254 subjects. The area of $\mathrm{F}$ score under ROC curve in the validation population was 0.7816 , as shown in Figure $3.95 \% \mathrm{Cl}$ was $[0.68,0.8852]$, specificity was 0.848 , sensitivity was 0.75 , and accuracy was 0.8461 , the positive likelihood ratio was 4.9332; the negative likelihood ratio: 0.2948 ; the diagnosis odds ratio: 16.7326 , positive predictive value was 0.0878 , and negative predictive value was 0.9943 . (Bootstrap resampling times $=500$ )

It can be seen that $\mathrm{F}$ score has a good predictive effect on fatty liver in the validated population.

\section{Discussion}

Liver function enzymes are important markers of the severity of many liver diseases, especially aspartate aminotransferase (AST) and alanine aminotransferase (ALT)(13). The study by Helene Gellert-Kristensen et al. found that the concentration of ALT has an important correlation with the risk of fatty liver, cirrhosis and $\mathrm{HCC}(14)$. And ALT is an independent related factor of metabolic syndrome, obesity, diabetes and other diseases $(15,16)$. Alcohol intake is an important factor leading to fatty liver and one of the important reasons leading to elevated ALT. Moderate alcohol consumption does not cause a significant increase in ALT, but long-term alcohol intake can cause an increase in ALT and liver changes(17-19). 
NAFLD is closely related to ALT activity and is a common cause of unexplained ALT elevation $(20,21)$. Unexplained elevated ALT should consider the possibility of NAFLD(16). This is also consistent with our experimental results, ALT is one of the most important factors related to fatty liver.

Studies by Muhammad et al. have shown that creatinine is significantly elevated in patients with fatty liver, which is obviously correlated with fatty liver(22). Creatinine is an important indicator of model for end-stage liver disease (MELD) score, which measures liver function and predicts survival in patients with liver disease(23-26).

NAFLD is closely linked with hepatic insulin resistance $(27,28)$. It is the liver manifestation of metabolic syndrome, and increased glucose is one of the important manifestations(29). Insulin resistance is a key pathogenic factor of metabolic syndrome and the most common risk factor for NAFLD(30-32). In patients with insulin resistance, insulin cannot inhibit liver glucose production, but it continues to stimulate adipogenesis, leading to hyperglycemia, hyperlipidemia, liver steatosis and type 2 diabetes(33, 34). However, in our study, insulin content was not an important correlation factor of fatty liver. This may be because the level of insulin does not directly reflect the liver insulin resistance like glucose $(35,36)$.

Researches showed that platelet count is related to NALFD and liver cirrhosis(37-39), and can reflect the degree of liver injury(40). Studies have also shown that platelet count is closely related to insulin resistance, and its severity and complications $(41,42)$. This may have the following reasons: $(1)$ the influence of portal hypertension; (2) splenic sequestration of platelets; (3) liver damage may also cause TPO release defects and reduce platelet production in the bone marrow(43-45).

There are also some shortcomings in this study, for example, the included population is from the NHANES database, and the model still needs prospective research verification. Whether there are other indicators that can improve the accuracy of the model also needs to be explored in the future, but at present, the model can predict the occurrence of fatty liver with satisfactory accuracy by using blood biochemical indicators.

\section{Conclusion}

F score has a good predictive effect on fatty liver, which can be used as an important means for the prevention and treatment of fatty liver, especially NAFLD in the future.

\section{Abbreviations}

1. NAFLD: non-alcoholic fatty liver disease

2. NASH: non-alcoholic steatohepatitis

3. NHANES: National Health and Nutrition Examination Surveys

4. ALT: Alanine Aminotransferase 
5. LDH: Lactate Dehydrogenase

6. AST: aspartate aminotransferase

7. MELD: model for end-stage liver disease

\section{Declarations}

Ethics approval and consent to participate

The data were obtained from NHANES database and no ethical review was required.

\section{Consent for publication}

Not applicable.

\section{Acknowledgement}

None.

\section{Availability of data and materials}

All data for the study can be obtained from the corresponding author and author

\section{Competing interests}

The authors declare that they have no competing interests.

\section{Funding}

None.

\section{Authors' contributions}

Study concept and design: Yan XU, Rong LIU.

Data extraction: Yan XU;

Data analysis and interpretation: Yan XU.

Drafting of the manuscript: Yan XU;

critical revision of the manuscript for important intellectual content: Rong LIU.

Statistical analysis: Yan XU. 
None.

\section{Authors' information}

Yan XU, Rong LIU

Department of Hepatopancreatobiliary Surgical Oncology, Chinese People's Liberation Army (PLA) General Hospital, Beijing 100853, China.

Corresponding author: Rong LIU

Email: L301liurong@126.com

Tel:86-15229386268

Address: 28 Fu Xing Road, Hai Dian District, Beijing 100853, China.

\section{References}

1. SCHULZE R J, MCNIVEN M A. Lipid Droplet Formation and Lipophagy in Fatty Liver Disease. SEMIN LIVER DIS 2019; 39(3): 283-90.

2. YOUNOSSI Z M, BLISSETT D, BLISSETT R, HENRY L, STEPANOVA M, YOUNOSSI Y, et al. The economic and clinical burden of nonalcoholic fatty liver disease in the United States and Europe. HEPATOLOGY 2016; 64(5): 1577-86.

3. SINGH S, SINGH P P, ROBERTS L R, SANCHEZ W. Chemopreventive strategies in hepatocellular carcinoma. Nat Rev Gastroenterol Hepatol 2014; 11(1): 45-54.

4. MICHELOTTI G A, MACHADO M V, DIEHL A M. NAFLD, NASH and liver cancer. Nat Rev Gastroenterol Hepatol 2013; 10(11): 656-65.

5. ALTAMIRANO J, BATALLER R. Alcoholic liver disease: pathogenesis and new targets for therapy. Nat Rev Gastroenterol Hepatol 2011; 8(9): 491-501.

6. SINGAL A K, BATALLER R, AHN J, KAMATH P S, SHAH V H. ACG Clinical Guideline: Alcoholic Liver Disease. AM J GASTROENTEROL 2018; 113(2): 175-94.

7. MARATOS-FLIER E. Fatty liver and FGF21 physiology. EXP CELL RES 2017; 360(1): 2-05.

8. TANG A, TAN J, SUN M, HAMILTON G, BYDDER M, WOLFSON T, et al. Nonalcoholic fatty liver disease: MR imaging of liver proton density fat fraction to assess hepatic steatosis. RADIOLOGY 2013; 267(2): 422-31.

9. DAY C P. Natural history of NAFLD: remarkably benign in the absence of cirrhosis. GASTROENTEROLOGY 2005; 129(1): 375-78.

10. EASL-EASD-EASO Clinical Practice Guidelines for the management of non-alcoholic fatty liver disease. J HEPATOL 2016; 64(6): 1388-402. 
11. CHALASANI N, YOUNOSSI Z, LAVINE J E, CHARLTON M, CUSI K, RINELLA M, et al. The diagnosis and management of nonalcoholic fatty liver disease: Practice guidance from the American Association for the Study of Liver Diseases. HEPATOLOGY 2018; 67(1): 328-57.

12. PAPATHEODORIDI M, CHOLONGITAS E. Diagnosis of Non-alcoholic Fatty Liver Disease (NAFLD): Current Concepts. Curr Pharm Des 2018; 24(38): 4574-86.

13. LIU Y, ZHAO P, CHENG M, YU L, CHENG Z, FAN L, et al. AST to ALT ratio and arterial stiffness in nonfatty liver Japanese population:a secondary analysis based on a cross-sectional study. LIPIDS HEALTH DIS 2018; 17(1): 275.

14. GELLERT-KRISTENSEN H, NORDESTGAARD B G, TYBJAERG-HANSEN A, STENDER S. High Risk of Fatty Liver Disease Amplifies the Alanine Transaminase-Lowering Effect of a HSD17B13 Variant. HEPATOLOGY 2020; 71(1): 56-66.

15. CLARK J M, BRANCATI F L, DIEHL A M. The prevalence and etiology of elevated aminotransferase levels in the United States. AM J GASTROENTEROL 2003; 98(5): 960-67.

16. LIU Z, QUE S, XU J, PENG T. Alanine aminotransferase-old biomarker and new concept: a review. INT J MED SCI 2014; 11(9): 925-35.

17. PENDINO G M, MARIANO A, SURACE P, CASERTA C A, FIORILLO M T, AMANTE A, et al. Prevalence and etiology of altered liver tests: a population-based survey in a Mediterranean town. HEPATOLOGY 2005; 41(5): 1151-59.

18. CLARK J M, BRANCATI F L, DIEHL A M. The prevalence and etiology of elevated aminotransferase levels in the United States. AM J GASTROENTEROL 2003; 98(5): 960-67.

19. ALATALO P I, KOIVISTO H M, HIETALA J P, PUUKKA K S, BLOIGU R, NIEMELA O J. Effect of moderate alcohol consumption on liver enzymes increases with increasing body mass index. AM J CLIN NUTR 2008; 88(4): 1097-103.

20. CHEN C H, HUANG M H, YANG J C, NIEN C K, YANG C C, YEH Y H, et al. Prevalence and etiology of elevated serum alanine aminotransferase level in an adult population in Taiwan. J Gastroenterol Hepatol 2007; 22(9): 1482-89.

21. LIU C M, TUNG T H, LIU J H, CHEN V T, LIN C H, HSU C T, et al. A community-based epidemiological study of elevated serum alanine aminotransferase levels in Kinmen, Taiwan. World J Gastroenterol 2005; 11(11): 1616-22.

22. ASGHAR M S, HASSAN M, RASHEED U, HAIDER K S, KHAN N A, KHALID F, et al. Impact of Fasting Lipid Profile on Chronic Kidney Disease Patients Having Fatty Liver Disease. Cureus 2020; 12(10): e11146.

23. PENG Y, QI X, GUO X. Child-Pugh Versus MELD Score for the Assessment of Prognosis in Liver Cirrhosis: A Systematic Review and Meta-Analysis of Observational Studies. Medicine (Baltimore) 2016; 95(8): e2877.

24. SUCANDY I, GIOVANNETTI A, SPENCE J, ROSS S, ROSEMURGY A. Does preoperative MELD score affect outcomes following robotic hepatectomy for liver tumors? J Robot Surg 2020; 14(5): 725-31. 
25. KESKIN S, CIFTCI O, MORAY G, MUDERRISOGLU H, HABERAL M. MELD-XI Score and Coronary Artery Disease Prevalence and Extent Among In-Hospital Patients With End-Stage Liver Failure Awaiting Transplant. EXP CLIN TRANSPLANT 2020; 18(Suppl 1): 88-92.

26. ACHARYA G, KAUSHIK R M, GUPTA R, KAUSHIK R. Child-Turcotte-Pugh Score, MELD Score and MELD-Na Score as Predictors of Short-Term Mortality among Patients with End-Stage Liver Disease in Northern India. Inflamm Intest Dis 2020; 5(1): 1-10.

27. RAFF E J, KAKATI D, BLOOMER J R, SHOREIBAH M, RASHEED K, SINGAL A K. Diabetes Mellitus Predicts Occurrence of Cirrhosis and Hepatocellular Cancer in Alcoholic Liver and Non-alcoholic Fatty Liver Diseases. J Clin Transl Hepatol 2015; 3(1): 9-16.

28. SAMUEL V T, SHULMAN G I. Nonalcoholic Fatty Liver Disease as a Nexus of Metabolic and Hepatic Diseases. CELL METAB 2018; 27(1): 22-41.

29. Executive Summary of The Third Report of The National Cholesterol Education Program (NCEP) Expert Panel on Detection, Evaluation, And Treatment of High Blood Cholesterol In Adults (Adult Treatment Panel III). JAMA 2001; 285(19): 2486-97.

30. PAGANO G, PACINI G, MUSSO G, GAMBINO R, MECCA F, DEPETRIS N, et al. Nonalcoholic steatohepatitis, insulin resistance, and metabolic syndrome: further evidence for an etiologic association. HEPATOLOGY 2002; 35(2): 367-72.

31. HAMAGUCHI M, KOJIMA T, TAKEDA N, NAKAGAWA T, TANIGUCHI H, FUJII K, et al. The metabolic syndrome as a predictor of nonalcoholic fatty liver disease. ANN INTERN MED 2005; 143(10): 72228.

32. LOMONACO R, ORTIZ-LOPEZ C, ORSAK B, WEBB A, HARDIES J, DARLAND C, et al. Effect of adipose tissue insulin resistance on metabolic parameters and liver histology in obese patients with nonalcoholic fatty liver disease. HEPATOLOGY 2012; 55(5): 1389-97.

33. BROWN M S, GOLDSTEIN J L. Selective versus total insulin resistance: a pathogenic paradox. CELL METAB 2008; 7(2): 95-96.

34. GASTALDELLI A, BALDI S, PETTITI M, TOSCHI E, CAMASTRA S, NATALI A, et al. Influence of obesity and type 2 diabetes on gluconeogenesis and glucose output in humans: a quantitative study. DIABETES 2000; 49(8): 1367-73.

35. TITCHENELL P M, LAZAR M A, BIRNBAUM M J. Unraveling the Regulation of Hepatic Metabolism by Insulin. Trends Endocrinol Metab 2017; 28(7): 497-505.

36. SEMPLE R K, SLEIGH A, MURGATROYD P R, ADAMS C A, BLUCK L, JACKSON S, et al. Postreceptor insulin resistance contributes to human dyslipidemia and hepatic steatosis. J CLIN INVEST 2009; $119(2): 315-22$.

37. GARJANI A, SAFAEIYAN A, KHOSHBATEN M. Association between platelet count as a noninvasive marker and ultrasonographic grading in patients with nonalcoholic Fatty liver disease. HEPAT MON 2015; 15(1): e24449.

38. MILOVANOVIC A T, STOJKOVIC L M, DUMIC I, JOCIC N, PAVLOVIC M A, DRAGASEVIC S, et al. Diagnostic Accuracy of Platelet Count and Platelet Indices in Noninvasive Assessment of Fibrosis in 
Nonalcoholic Fatty Liver Disease Patients. Can J Gastroenterol Hepatol 2017; 2017: 6070135.

39. MALEHMIR M, PFISTER D, GALLAGE S, SZYDLOWSKA M, INVERSO D, KOTSILITI E, et al. Platelet GPIbalpha is a mediator and potential interventional target for NASH and subsequent liver cancer. NAT MED 2019; 25(4): 641-55.

40. KARASU Z, TEKIN F, ERSOZ G, GUNSAR F, BATUR Y, ILTER T, et al. Liver fibrosis is associated with decreased peripheral platelet count in patients with chronic hepatitis B and C. Dig Dis Sci 2007; 52(6): 1535-39.

41. BUDAK Y U, POLAT M, HUYSAL K. The use of platelet indices, plateletcrit, mean platelet volume and platelet distribution width in emergency non-traumatic abdominal surgery: a systematic review. Biochem Med (Zagreb) 2016; 26(2): 178-93.

42. EMINLER A T, USLAN M I, AYYILDIZ T, IRAK K, KIYICI M, GUREL $S$, et al. Mean platelet volume is an important predictor of hepatitis C but not hepatitis B liver damage. J RES MED SCI 2015; 20(9): 86570.

43. GARJANI A, SAFAEIYAN A, KHOSHBATEN M. Association between platelet count as a noninvasive marker and ultrasonographic grading in patients with nonalcoholic Fatty liver disease. HEPAT MON 2015; 15(1): e24449.

44. WEKSLER B B. Review article: the pathophysiology of thrombocytopenia in hepatitis C virus infection and chronic liver disease. Aliment Pharmacol Ther 2007; 26 Suppl 1: 13-19.

45. GIANNINI E, BORRO P, BOTTA F, FUMAGALLI A, MALFATTI F, PODESTA E, et al. Serum thrombopoietin levels are linked to liver function in untreated patients with hepatitis $C$ virus-related chronic hepatitis. J HEPATOL 2002; 37(5): 572-77.

\section{Figures}

A

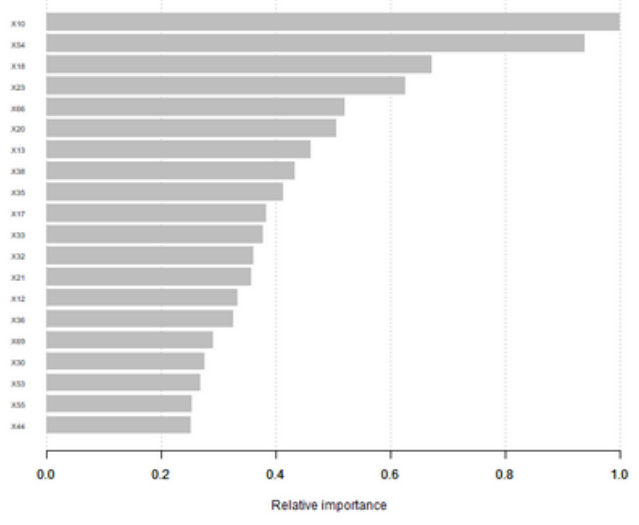

B

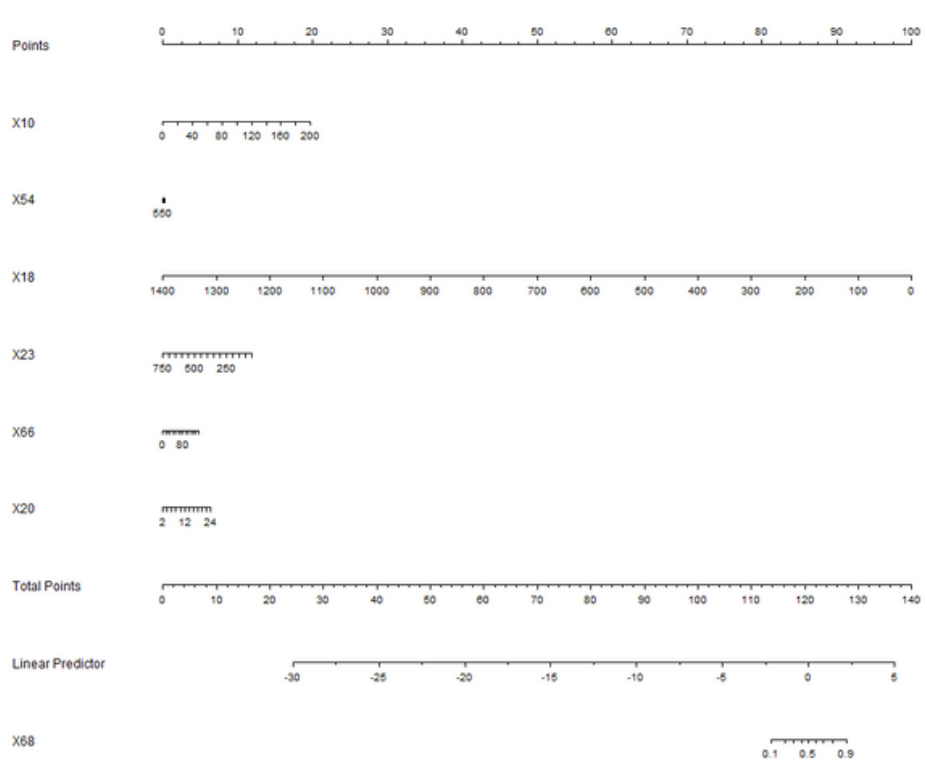


Figure 1

a: Correlation of various factors and fatty liver. X10: Alanine Aminotransferase (ALT) , X54: Platelet count, X18: Creatinine, X23: Lactate Dehydrogenase (LDH), X66: HS C-Reactive Protein, X20: Glucose, X13:

Aspartate Aminotransferase (AST), X38: Monocyte percent, X35: Body Mass Index, X17: Creatine Phosphokinase (CPK), X33: Uric acid, X32: Triglycerides, X21: Gamma Glutamyl Transferase (GGT), X12: Alkaline Phosphatase (ALP), X36: White blood cell count, X69: Total Cholesterol, X30: Cholesterol, X53:

Red cell distribution width, X55: Mean platelet volume, X44: Segmented neutrophils num. $b$ : The Alignment Diagram of the influence of various factors on fatty liver. X10: Alanine Aminotransferase (ALT) , X54: Platelet count, X18: Creatinine, X23: Lactate Dehydrogenase (LDH), X66: HS C-Reactive Protein, X20: Glucose, X68: Fatty liver.

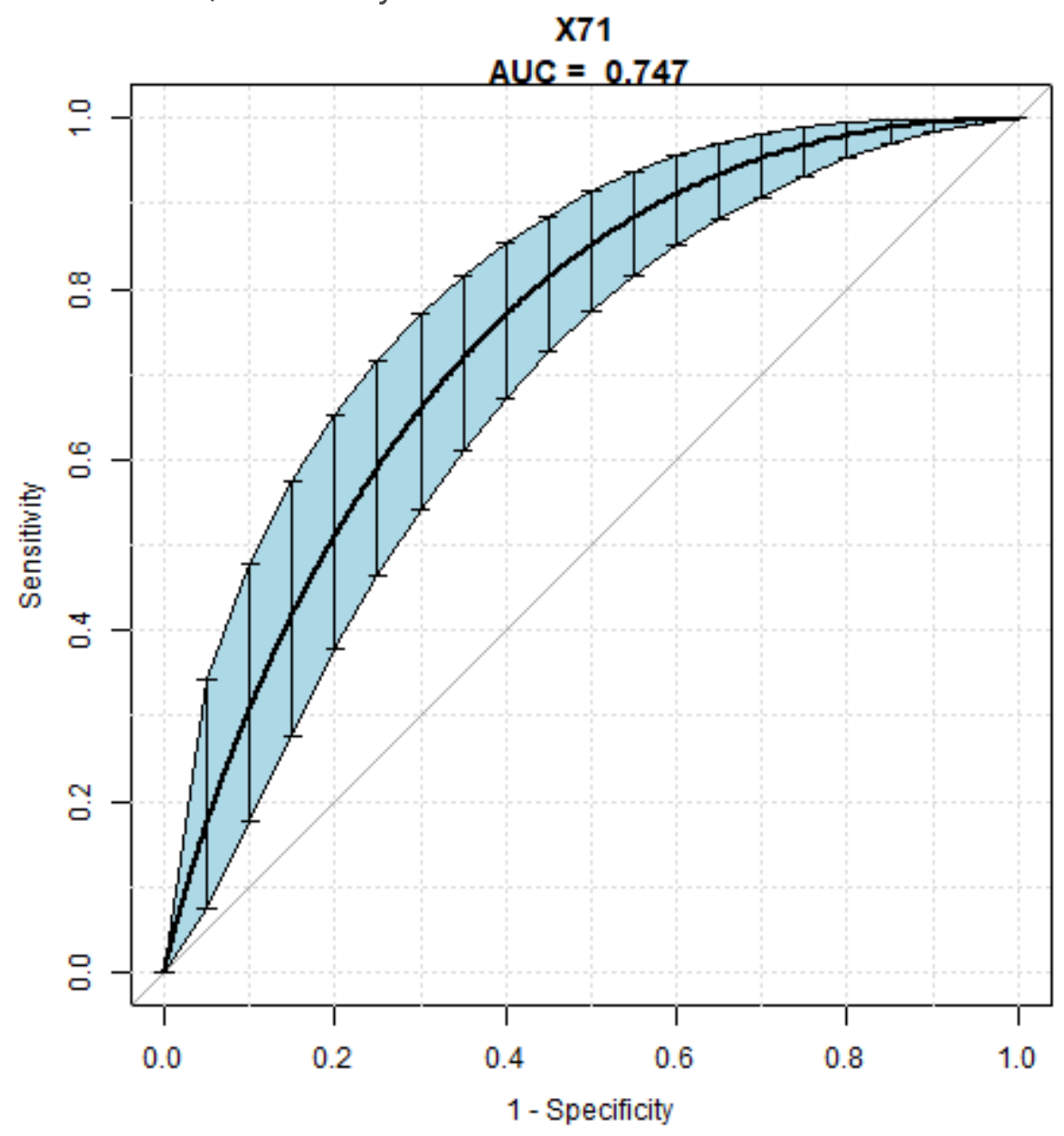

Figure 2

The ROC curve of the prediction model in the model building population. 


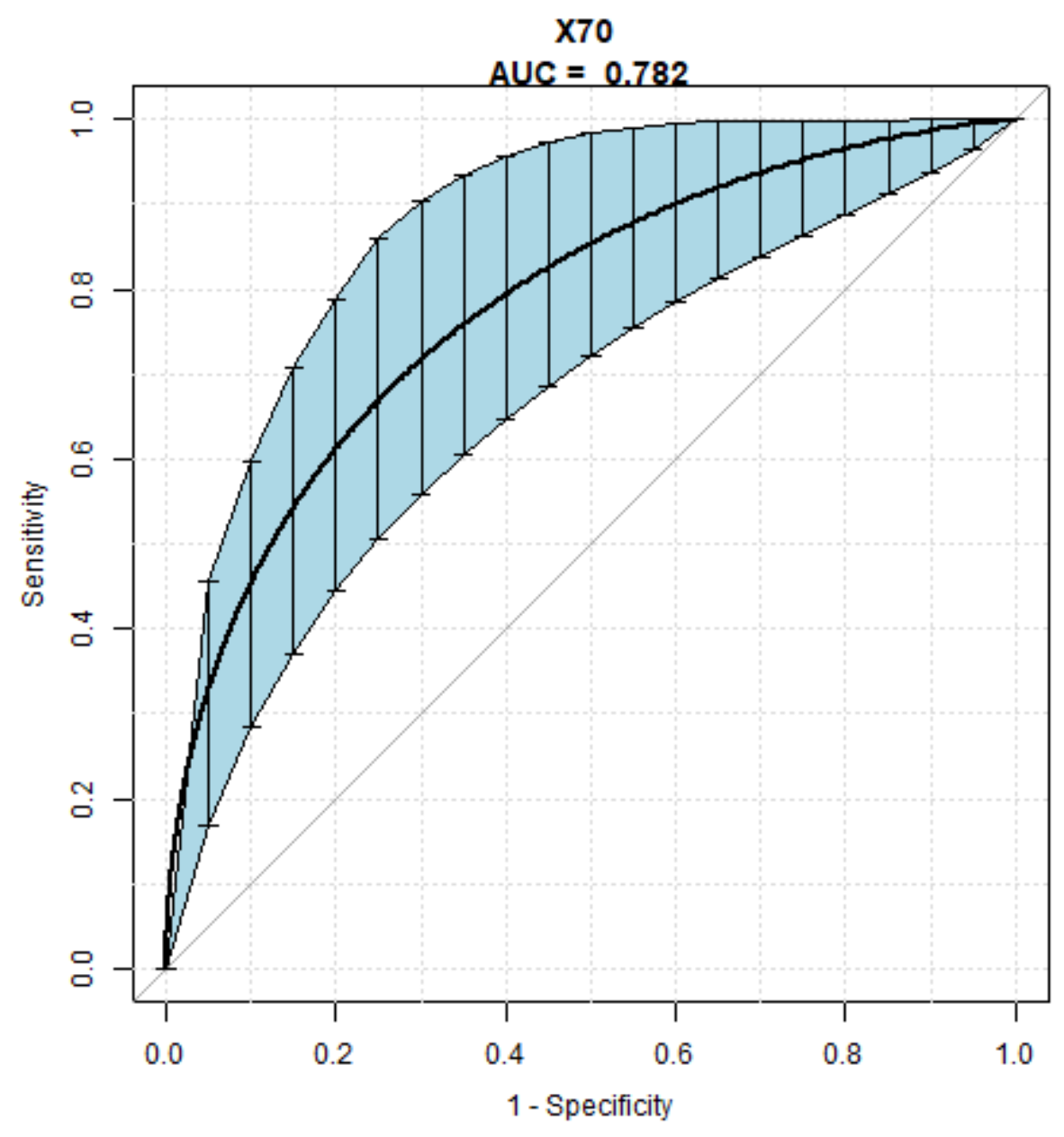

Figure 3

The ROC curve of the prediction model in the validation model population. 